\title{
$\begin{array}{ll}\text { Research Square } & \text { Preprints are preliminary reports that have not undergone peer review. } \\ \text { They should not be considered conclusive, used to inform clinical practice, }\end{array}$ or referenced by the media as validated information.
}

\section{Midface Resection And Reconstruction In Head And Neck Oncology: A 20 Years Single Institution Experience}

G. Vakis ( $\sim$ g_vakis@hotmail.com )

Evangelismos General Hospital of Athens

M. Kotrotsiou

Evangelismos General Hospital of Athens

F. Neamonitou

St. Savvas Anticancer Hospital of Athens

D. Papala

St. Savvas Anticancer Hospital of Athens

S. Stavrianos

St. Savvas Anticancer Hospital of Athens

Research Article

Keywords: midface tumors, resection, reconstruction

Posted Date: January 14th, 2022

DOI: https://doi.org/10.21203/rs.3.rs-1223326/v1

License: (c) (1) This work is licensed under a Creative Commons Attribution 4.0 International License. Read Full License 


\section{Abstract}

Background: Midface tumors are relatively uncommon as midface comprises less than $1 \%$ of all malignant tumors and incorporate a distinct group of lesions, with a high variety of histological types and biological behavior. The purpose of the study is to present our experience in managing patients with advanced midface tumors for a 20 -year period.

Materials \& Methods: From January 2000 to May 2020, we performed 72 excisions and reconstructions in 36 patients where their medical records were reviewed by the head and neck oncology clinic. The commonest anatomical site of the primary was the maxilla in 19 patients and bilaterally in 5 patients. In 15 patients there was an orbital and anterior fossa extension. In 6 patients there was a parotid and middle ear extension and in 1 patient there was a lip involvement.

Results: Surgical resection included maxillectomy in the majority of the cases in combination with orbital exenteration or orbitectomy and anterior fossa resection. In 8 cases parotidectomy and mastoidectomy/ core petrosectomy was performed. One patient was subjected to total petrosectomy. Reconstruction was performed with radial forearm osteocutaneous free flap in 4 cases, latissimus with scapular bone flap in one case, lengthening temporalis myoplasty in 19 cases, rectus femoris in one case and anterolateral thigh flap in 5 cases in combination with temporalis and vastus lateralis in one case respectively and bilateral karapandzic flap in 1 case. The patients were followed-up from 2005 to 2020 . To date, 23 patients $(63.8 \%)$ are disease free with no recurrences of the disease and $4.4 \%$ of all patients presented disease recurrence during the follow-up period.

Conclusions: In conclusion midface resections are safely performed with a combination of microvascular and dynamic reconstruction of the face offering our patients quality of life improvement.

Level of Evidence: Level V, therapeutic study

\section{Introduction}

Midface tumors are relatively uncommon (less than $1 \%$ of all malignant tumors) and incorporate a distinct group of lesions, with a wide variety of histological types and biological behavior. Since the beginning of the 20th century, the better knowledge of pathology and the advances in imaging and reconstructive surgical techniques have improved the management and the prognosis of midfacial tumors [1-3].

The midface is a complex anatomical region, including several deeply positioned intercommunicating anatomical spaces, allowing tumors to enlarge without causing symptoms until final stages of the disease. More specifically, the anatomical relationships of the midface with the oral, antral, nasal, and anterior and middle cranial cavities affect the clinical presentation, the treatment and the outcome of midface tumors. Thus, most patients present to our department with advanced stages of the disease 
making their management (tumor resection, reconstruction, rehabilitation and cosmesis) very challenging $[4,5]$.

The surgical goals for treating neoplasias are sufficient exposure of the tissues allowing full excision of the tumor, preserving functional anatomy and minimizing morbidity and facial scarring. If the tumoral excision is not achievable, the goal is the functional reconstruction of the defect which may improve the rehabilitation of the patients [6]. Preoperative planning requires a detailed knowledge of the local anatomy along with the extent and the type of the neoplasia. The malignant midfacial tumors must be excised with a margin of one anatomical plane beyond the tumor in three dimensions (in terms of structure, color and texture) [7]. Basal cell carcinoma, squamous cell carcinoma, malignant melanoma and sarcoma considered to be malignant tumors. Four main types of surgical approaches are used to excise midfacial tumors: Intraoral approach (direct excision, facial degloving, Le Fort I maxillotomy), transfacial approach (modified Ferguson, maxillary swing), temporal approach and craniofacial approach [7].

Resection of midfacial tumors is challenging and can generate large defects with severe functional and aesthetic outcomes for patients. Although cancer treatment is the primary aim, aesthetical restoration is vital for the patients' survival, and quality of life [8]. Despite the evolution of microsurgical techniques, reconstruction of sense organs such as the entire nose or the eye is technically demanding, with unpredictable final results [9-11]. Today, many patients with advanced midfacial tumors can undergo successful reconstruction after free flap transfer, gaining an intelligible speech, a functional oral CVT and a normal diet [10], and acceptable aesthetic outcome.

The purpose of the study is to present our experience and evaluate the results of all the patients with advanced midface tumors treated in our department for the last two decades (2000-2020).

\section{Patients \& Methods}

The medical records of 36 consecutive patients admitted for the management of midface tumors were reviewed by the head and neck oncology clinic. Demographic data of the patients were recorded. The site of the tumor along with the surgical approach and reconstruction technique were also recorded. An informed consent was obtained in this study, which was conducted in accordance with the tenets of Declaration of Helsinki. 30/35 of our patients had received preoparative XRT and Chemotherapy.

A total of 36 patients were included in the study population ( 26 male and 10 female), with a mean age of 67 years (age range 50 to 84). The commonest anatomical site of the primary was the maxilla in 19 patients (in 5 patients bilaterally). In 15 patients, there was an orbital and anterior fossa tumor extension. In 6 patients, there was a parotid and middle ear / middle fossa extension and one patient had a lip involvement. Figure 1 shows a case of squamous cell carcinoma located in the hard palate. The most common presentations were intraoral and facial swelling, pain, and ulceration. 
In the majority of the cases, surgical resection included maxillectomy in combination with orbital exenteration or orbitectomy and anterior fossa resection. In 8 cases, parotidectomy and petrosectomy were performed and in one case, the patient was subjected to total petrosectomy. All patients underwent modified radical neck dissection (mRND) type II. Figure 2 shows a case of maxillectomy through a modified Fergusson approach.

Reconstruction was performed with radial forearm osteocutaneous free flap in 4 cases, latissimus dorsi with scapular bone flap in one case, dynamic temporalis in 19 cases, rectus in one case and anterolateral thigh flap in 5 cases in combination with temporalis and vastus lateralis in one case respectively (Table 1).

There were 5 paramedian flaps performed for facial skin reconstruction. There were 1 nasal flap, 1 scalp flap, 1 medial forehead flap and 2 bilateral karapandzic flap performed for accessory reconstruction. Finally, there were 6 facial nerve reconstructions performed with the use of cervical plexus nerve grafts all simultaneously with lengthening temporalis myoplasty and Mcloughlin tarsorrhaphies of the eyelids.

\section{Results - Follow-up}

With a mean follow-up of 15 years, 23 patients out of $36(63.8 \%)$ are disease free with no recurrences of the disease and 6 of patients presented disease recurrence during the follow-up period and received chemotherapy for palliation and 5 patients lost in follow-up.

\section{Discussion}

We have presented the 20-year experience of a tertiary referral center in the surgical management of midfacial tumors. Neoplasias of the midface have a variety of tumor cells biological aggressiveness and their different response to the surgical treatment create the need of a management plan tailored to every patient. Since the beginning of the century, Sigmund Freud and the President of the USA were the first patients treated for maxillary tumor [12]. Squamous cell carcinomas represent more than $90 \%$ of all malignant neoplasms of the oral cavity and have a high correlation with alcohol consumption and smoking [13]. The surgical resection of midfacial tumors along with the subsequent reconstruction is a demanding and challenging procedure that must be carried out by specialized surgeons.

As midfacial neoplasias tend to be asymptomatic until late stages, the primary tumor has often spread into adjacent structures and anatomical spaces; The Ohngren's classification, a prognostic examination, is an imaginary plane extending $\mathrm{b} / \mathrm{n}$ medial canthus of eye and angle of mandible. Supra structural growth situates above this plane have poor prognosis and infra structural growth below this plane have better prognosis; It is vital to use every available diagnostic examination to depict the spread of the tumor and make the appropriate surgical plan [14] in more details. Biopsy results are essential for the clarification of the type of the tumor, which will determine the surgical approach. Flexible endoscopy can be used to assess or biopsied the lesions from nasal or naso-pharyngeal tumors. Standard $\mathrm{x}$-rays can 
show bone destruction and opacification of sinuses. CT scans may help the assessment of soft tissues, bony involvement, local spread and node status. MRI scans may differentiate inflammation, oedema, and mucous from tumor and peri-neural spread, as well as ruling out intracranial extension. Deeply located tumors may be accessed by a CT-guided needle biopsy. Angiography has a limited role and it is mainly addressed to vascular tumors, such as juvenile angiofibroma, for the identification and embolization of feeding vessels [15].

Maxillectomy is used to remove damaged parts pf the maxilla due to cancerous tissues. The first maxillectomy was performed in the late $1820 \mathrm{~s}$, and since then a significant evolution of midface surgical approaches has been observed. Based on the Algorithm of Corderio, removal of midfacial neoplasias may be classified as partial, subtotal, total, or radical maxillectomy [16]. In partial maxillectomy, part of maxilla is removed leaving one or more bony walls in place. It often includes alveolectomy or medial maxillectomy. Subtotal maxillectomy is defined as a partial maxillectomy with total palatectomy. Total maxillectomy involves removal of the whole maxilla. Extended or radical maxillectomy, described in 1954, includes a total maxillectomy and palatectomy defect with loss of orbital support or eye. When maxilla is removed, a prosthesis obturator is used to seal the opening between mouth and nose, in order to prevent fluid and food ascending to the nose, to improve speech postoperatively and to provide a better aesthetic image. In addition, tumor involving the orbital periosteum is an indication of orbital exenteration. Maxillectomy in combination with orbital exenteration or orbitectomy and anterior fossa resection were mostly used in our case series $[17,18]$.

Excision of midfacial tumors can be performed through four main surgical approaches. Intraoral approaches include direct excision, facial degloving, and LeFort 1 maxillotomy. Subtotal maxillectomy via transfacial approach be used for early diagnosed and well localized intraoral tumors. Facial degloving approach, popularized in 1970, provides access to both maxilla and the nasal cavity, allowing complete bilateral exposure of the midfacial skeleton, without any visible incisions [19]. Zachariah et al reported excellent outcome with this approach in 9 patients [20]. LeFort 1 maxillotomy is used to approach nasopharyngeal tumors through osteotomy of the maxilla, without facial incisions [21-23]. Transfacial approaches include the modified Fergusson approach which, through a lateral rhinotomy incision extending infraorbitally, may expose the whole maxilla [24] while the maxillary swing provides access to the nasopharynx and the skull base $[25,26]$. The temporal approach, first mentioned in 1985, provides access to the posterior maxilla, the retromaxillary region region, and the orbits, without disturbing functional anatomy nor facial incisions $[27,28]$. The craniofacial approach provides access to intracranial portions of midfacial tumors, with stroke, epilepsy and intracranial infections as reported complications [28].

Postoperative facial disfigurement affects social life significantly [8]. However, patients treated with midfacial implant-retained prostheses state that the prosthesis removes their fear of unwanted attention and increases their overall quality of life $[10,29]$. Subjective health-related quality of life was found reduced in comparison with preoperative facies when the acquired defects were located in the region of the eye and the nose [30]. 
The order of reconstruction in midfacial tumors depends on the size of the defect [31, 32]. Maxillary defects are characterized by the extent of resection of critical midfacial components. Reconstruction of the infraorbital rim and orbital floor optimises appearance and function [1]. There are many available reconstruction options based on Algorithm of Corderio [6]: Prosthetic obturation, autogenous flaps (pedicled flaps, vascularized free flaps, non-vascularized autogenous bone grafts or combinations), allografts and alloplastic materials (titanium mesh, dental implants). The advantages of the obturators in functional rehabilitation should not be overlooked. The use of obturators shortens the duration of surgery and hospitalization, provides better visualization for follow-up, facilitates speech and swallowing and restores cosmetic appearance. They are placed intraoperatively and they are removed in 2 weeks. Then an interim obturator may be used until final healing, when a definitive obturator is placed about 6-12 months postoperatively $[17,18]$.

Many pedicled flaps, local or regional, have been used for midface and maxillary reconstruction. They can be easily harvested; however, they are limited by their feeding vessels. Local flaps include buccal fat pad flaps, palatal island flaps, nasolabial flaps, tongue flaps and uvula flaps. Regional flaps include submental flaps, temoproparietal-galea flaps, temporalis flaps, platysma flaps, masseter flaps, sternocleidomastoid flaps, trapezius flaps, deltopectoral flaps and pectoralis major myocutaneous flaps, successfully used to cover midface and maxillary defects [33]. We have used lengtheming temporalis myoplasty flaps in 18 patients in our study, as it an easy flap with reliable blood supply and abhidden incision.

Evolution of surgical techniques with the applications of free flaps has broadened the horizons of reconstruction radical surgery, as they can be successfully used to cover large tissue defects after radical midface surgeries. Parts of the skull base may be removed and the risk of meningitis is minimized when the cavities are sealed with vascularised tissues $[34,35]$. Vascularized free flaps include radial forearm free flaps, radial forearm osteo-fascio-cutaneous flaps, rectus abdominis flaps, fibula osteo-cutaneous flaps, scapular osteo-myocutaneous flaps and vascularized iliac crests [36-38]. We have chosen to use radial forearm osteo-fascio-cutaneous flaps in 4 cases, as it is useful for smaller reconstructions, it can be easily harvested and often provides good skin color match for head and neck reconstruction. Moreover, Yetzer $\mathrm{J}$ et al presents its usefulness in palatal defects [39]. In one case, we have used a rectus abdominis flap providing an appropriate tissue bulk with a pliability while it may cause abdominal weakness and hernia formation [36]. Moreover, in 5 cases with posterior palatomaxillectomy defects, we have used an anterolateral thigh flap, which provides significant tissue bulk and a long pedicle, allowing the primary closure of the donor site $[14,36]$.

Complications during treatment stages are not uncommon and patients should be informed about the possibility of the necessitation of multiple surgical procedures before the final outcome [14] ${ }^{14}$. Total failure of the flap is a rare but severe complication, often caused by thrombosis of the flap vessels and demands intensive flap checks, especially in the first 3 postoperative days [40]. Costa et al reported $4 \%$ loss of flap in 24 years [41]. No such complication was observed in our study. 
Our study has a limitation. This is a retrospective case series, with no comparison group. We believe that the experience of a tertiary referral center, such as ours, is valuable for the formulation of management protocols and the provision of guidelines for the appropriate choice of surgical management.

In conclusion, tumors of the midface encompass a diverse group of neoplasias. Surgery is the gold standard of treatment and its goals are complete oncological resection of the tumor and surgical reconstruction is essential in restoring quality of life and social functioning of patients with extensive midfacial defects. Optimal management of patients with midfacial defects should involve a multidisciplinary approach and the patients should be informed about all surgical options and likely outcomes. The results of our study have confirmed that surgical treatment may have satisfactory results when performed by experienced and specialized surgeons in tertiary centers. Midface resection can be safely performed with a combination of microvascular and dynamic reconstruction of the face offering our patients a better quality of life.

\section{Declarations}

\section{Funding}

The authors did not receive support from any organization for the submitted work.

\section{Conflicts of interest/Competing interests}

The authors declare that they have no known competing financial interests or personal relationships that could have appeared to influence the work reported in this paper.

\section{Availability of data and material (data transparency)}

All data is available upon request.

(All authors are requested to make sure that all data and materials as well as software application or custom code support their published claims and comply with field standards. Please note that journals may have individual policies on (sharing) research data in concordance with disciplinary norms and expectations.)

\section{Code availability}

Not applicable

\section{Authors' contributions (optional)}

All authors contributed to the study conception and design. Material preparation, data collection and analysis were performed by [full name], [full name] and [full name]. The first draft of the manuscript was written by [full name] and all authors commented on previous versions of the manuscript. All authors read and approved the final manuscript. 
This experimental protocol was approved by the Medical Committee of General Anticancer Hospital of Athens "Saint Savvas"

\section{Informed consent was obtained from all participants for both study participation and publication of identifying information/images}

\section{References}

1. Foster RD, Anthony JP, Singer MI, et al. Reconstruction of complex midfacial defects. Plast Reconstr Surg 1997;99:1555-65.

2. Lorant JA, Roumanas E, Nishimura R, et al. Restoration of oral function after maxillectomy with osseous integrated implant retained maxillary obturators. Am J Surg 1994; 168:412-4.

3. Jortay A, Coessens B, Greant P, et al. Use of osteomuscular free flaps after extended maxillectomy and craniofacial resection. About two cases. Acta Chir Belg 1994; 94:236-9.

4. Levesque AY, de la Torre JI. Midface anatomy, aging, and aesthetic analysis. Facial Plast Surg Clin North Am 2015; 23:129-36.

5. Stavrianos SD, Camilleri IG, McLean NR, et al. Malignant tumours of the maxillary complex: an 18year review. Br J Plast Surg 1998; 51:584-8.

6. Cordeiro PG, Disa JJ. Challenges in midface reconstruction. Semin Surg Oncol 2000; 19:218-25.

7. Futran ND, Mendez E. Developments in reconstruction of midface and maxilla. Lancet Oncol 2006; 7:249-58.

8. Van den Elzen ME, Versnel SL, Hovius SE, et al. Adults with congenital or acquired facial disfigurement: impact of appearance on social functioning. J Craniomaxillofac Surg 2012; 40:77782.

9. Ethunandan M, Downie I, Flood T. Implant-retained nasal prosthesis for reconstruction of large rhinectomy defects: the Salisbury experience. Int J Oral Maxillofac Surg 2010; 39:343-9.

10. Goiato MC, de Carvalho Dekon SF, de Faria Almeida DA, et al. Patients' satisfaction after surgical facial reconstruction or after rehabilitation with maxillofacial prosthesis. J Craniofac Surg 2011; 22:766-9.

11. Sinn DP, Bedrossian E, Vest AK. Craniofacial implant surgery. Oral Maxillofac Surg Clin North Am 2011; 23:321-35, vi-vii.

12. Davenport JC. The prosthetic care of Sigmund Freud. Br Dent J 1992; 172:205-7.

13. Llewellyn CD, Johnson NW, Warnakulasuriya KA. Risk factors for squamous cell carcinoma of the oral cavity in young people-a comprehensive literature review. Oral Oncol 2001; 37:401-18.

14. Chang El, Hanasono MM. State-of-the-art reconstruction of midface and facial deformities. J Surg Oncol 2016; 113:962-70.

15. Frunza A, Slavescu D, Lascar I. Aggressive tumor of the midface. Eplasty 2014; 14:ic26. 
16. Bridgeman AM, Murphy MJ, Sizeland A, et al. Midfacial tumours: a review of 72 cases. $\mathrm{Br} \mathrm{J}$ Oral Maxillofac Surg 2000; 38:94-103.

17. Cordeiro PG, Chen CM. A 15-year review of midface reconstruction after total and subtotal maxillectomy: part II. Technical modifications to maximize aesthetic and functional outcomes. Plast Reconstr Surg 2012; 129:139-47.

18. Cordeiro PG, Chen CM. A 15-year review of midface reconstruction after total and subtotal maxillectomy: part I. Algorithm and outcomes. Plast Reconstr Surg 2012; 129:124-36.

19. Casson PR, Bonanno PC, Converse JM. The midface degloving procedure. Plast Reconstr Surg 1974; 53:102-3.

20. Zachariah T, Neelakandan RS. Utility of the Midface Degloving Approach for Extended Exposure in Maxillary Pathologies. J Maxillofac Oral Surg 2020; 19:217-24.

21. Drommer RB. The history of the "Le Fort I osteotomy". J Maxillofac Surg 1986; 14:119-22.

22. Sasaki CT, Lowlicht RA, Astrachan DI, et al. Le Fort I osteotomy approach to the skull base. Laryngoscope 1990; 100:1073-6.

23. Brown DH. The Le Fort I maxillary osteotomy approach to surgery of the skull base. J Otolaryngol 1989; 18:289-92.

24. Mertz JS, Pearson BW, Kern EB. Lateral rhinotomy. Indications, technique, and review of 226 patients. Arch Otolaryngol 1983; 109:235-9.

25. Wei WI, Lam KH, Sham JS. New approach to the nasopharynx: the maxillary swing approach. Head Neck 1991; 13:200-7.

26. Lam KH, Lau WF, Yue CP, et al. Maxillary swing approach to the orbit. Head Neck 1991; 13:107-13.

27. Obwegeser HL. Temporal approach to the TMJ, the orbit, and the retromaxillary-infracranial region. Head Neck Surg 1985; 7:185-99.

28. Janecka IP, Sen CN, Sekhar LN, et al. Facial translocation: a new approach to the cranial base. Otolaryngol Head Neck Surg 1990; 103:413-9.

29. Goiato MC, Pesqueira AA, Ramos da Silva C, et al. Patient satisfaction with maxillofacial prosthesis. Literature review. J Plast Reconstr Aesthet Surg 2009; 62:175-80.

30. Klein M, Menneking $H$, Spring A, et al. [Analysis of quality of life in patients with a facial prosthesis]. Mund Kiefer Gesichtschir 2005; 9:205-13.

31. Motiee-Langroudi M, Harirchi I, Amali A, et al. Reconstruction of Midface and Orbital Wall Defects After Maxillectomy and Orbital Content Preservation With Titanium Mesh and Fascia Lata: 3-Year Follow-Up. J Oral Maxillofac Surg 2015; 73:2447 e1-5.

32. Stern SJ, Goepfert H, Clayman G, et al. Orbital preservation in maxillectomy. Otolaryngol Head Neck Surg 1993; 109:111-5.

33. Wei W, Qiu Y, Fang Q, et al. Pectoralis major myocutaneous flap in salvage reconstruction following free flap failure in head and neck cancer surgery. J Int Med Res 2019; 47:76-83. 
34. Konno A, Togawa K, lizuka K. Primary reconstruction after total or extended total maxillectomy for maxillary cancer. Plast Reconstr Surg 1981; 67:440-8.

35. Vincent A, Burkes J, Williams F, et al. Free Flap Reconstruction of the Maxilla. Semin Plast Surg 2019; 33:30-37.

36. Chana JS, Odili J. Perforator flaps in head and neck reconstruction. Semin Plast Surg 2010; 24:23754.

37. Genden EM. Reconstruction of the mandible and the maxilla: the evolution of surgical technique. Arch Facial Plast Surg 2010; 12:87-90.

38. Miles BA, Gilbert RW. Maxillary reconstruction with the scapular angle osteomyogenous free flap. Arch Otolaryngol Head Neck Surg 2011; 137:1130-5.

39. Yetzer J, Fernandes R. Reconstruction of orbitomaxillary defects. J Oral Maxillofac Surg 2013; 71:398-409.

40. Cannady SB, Lamarre E, Wax MK. Microvascular Reconstruction: Evidence-Based Procedures. Facial Plast Surg Clin North Am 2015; 23:347-56.

41. Costa $H$, Zenha $H$, Sequeira $H$, et al. Microsurgical reconstruction of the maxilla: Algorithm and concepts. J Plast Reconstr Aesthet Surg 2015; 68:e89-e104.

\section{Table}

Due to technical limitations, table 1 is only available as a download in the Supplemental Files section.

\section{Figures}




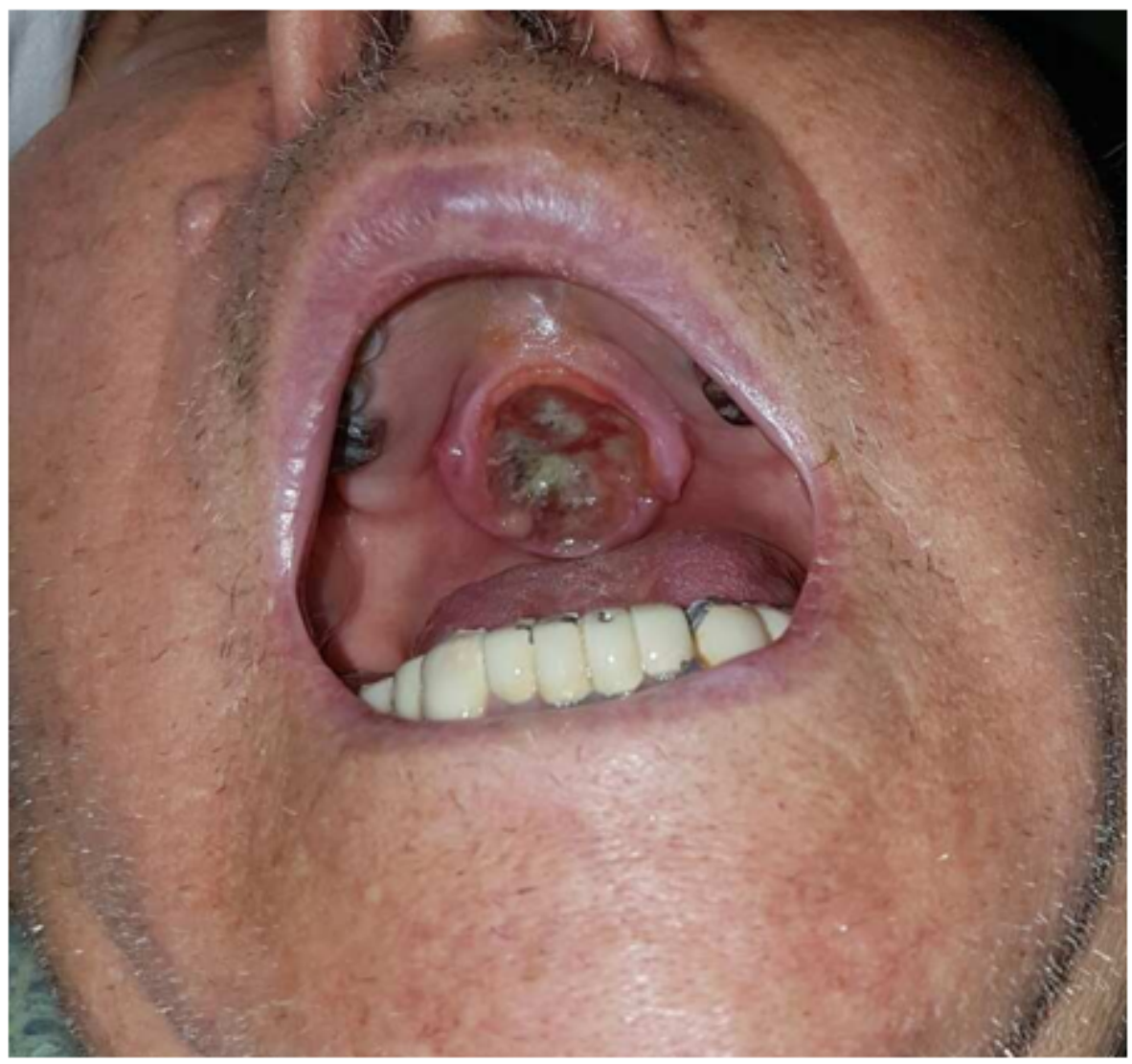

Figure 1

Squamous cell carcinoma located in the hard palate 


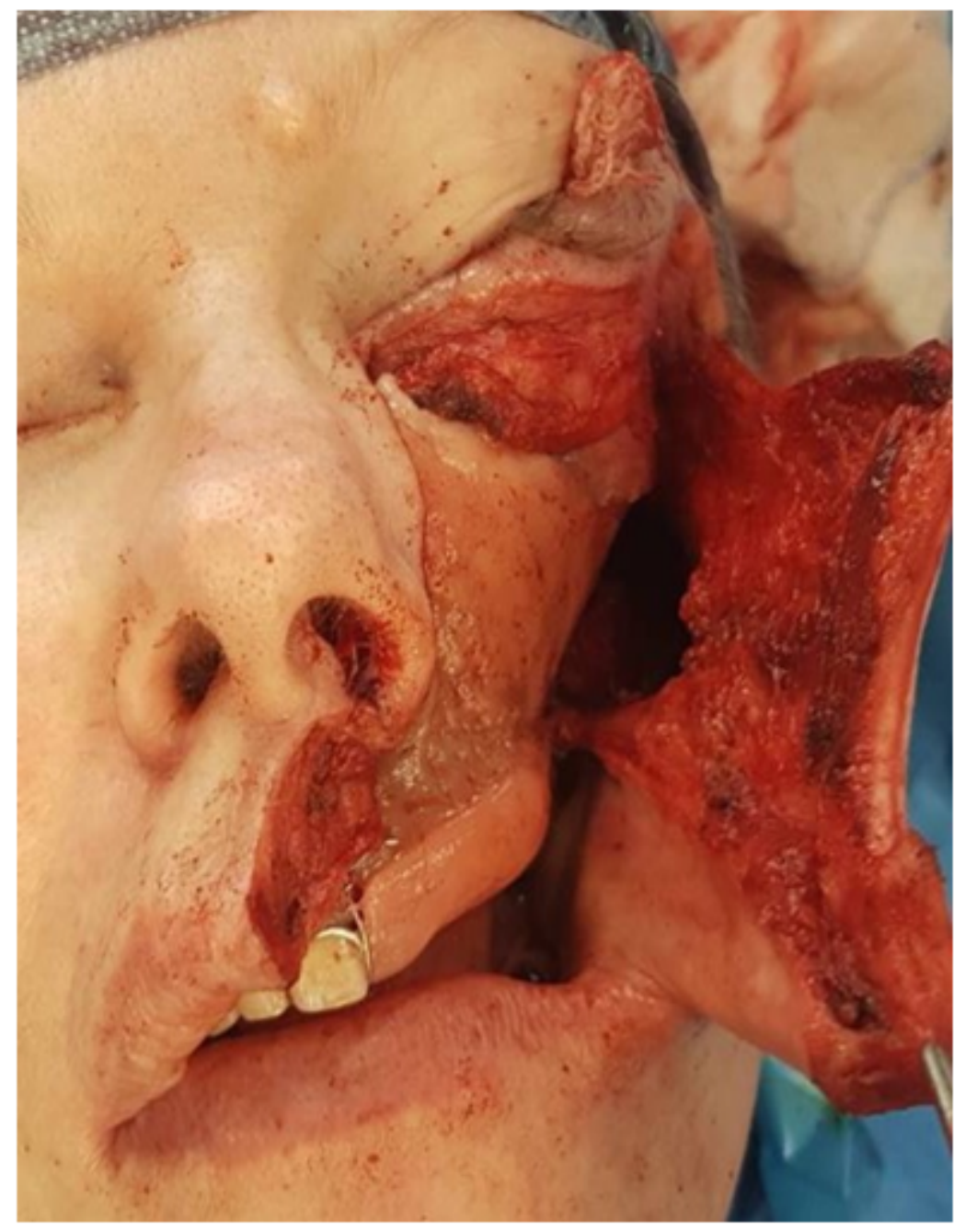

Figure 2

Case of maxillectomy through a modified Fergusson approach

\section{Supplementary Files}

This is a list of supplementary files associated with this preprint. Click to download.

- Table1.png 